\title{
DESARROLLO FINANCIERO Y ECONOMIA AGRARIA DE EXPORTACION EN EL PERU, 1884-1950*
}

\author{
ALFONSO W. QUIROZ \\ Baruch College
}

\section{RESUMEN}

Al analizar las fluctuaciones ciclicas del desarrollo financiero peruano y su relación con la economía durante una fase principalmente agroexportadora, se intenta contribuir al debate sobre el sector de exportación y su contribución al desarrollo económico latinoamericano. La evidencia indica que las instituciones y grupos financieros domésticos contribuyeron a una relativa diversificación de la economía y ofrecieron un grado de competencia a intereses financieros foráneos. Es más, el reemplazo del modelo exportador por uno de sustitución de importaciones trajo consigo mayor concentración financiera y políticas financieras adversas al desarrollo financiero.

\section{ABSTRACT}

The analysis of the cyclical fluctuatios in Peruvian financial development, and their relationship with the mainly agroexport economy, seeks to contribute to the discussion of the developmental role of Latin American export models. The major findings indicate that domestic financial institutions and elite groups contributed to a relative conomic diversification and offered a degree of competition to foreign financial interests. Moreover, the decline of the agroexport model led to a hardly autonomous import-substitution model that resulted in increased financial concentration and policies adverse to financial development.

En el estudio de la historia económica de Latinoamérica, el análisis del papel que desempeñó el sector exportador como promotor de desarrollo ha entrado en una estimulante nueva fase. Recientemente se han realizado considerables avances en el entendimiento de las economias de exportación,

* La investigación en Perú fue posible gracias a una beca para investigación del Consejo de Investigación de Ciencias Sociales, 1987. 
que son contrarios a la opinión de que la exportación especializada era la causa principal del subdesarrollo y la dependencia. Los nuevos estudios han demostrado el impacto del aumento de la importación sobre una adjudicación cada vez más eficaz de los factores nacionales de producción ${ }^{1}$, la mejora en las redes de transporte ${ }^{2}$, la diversificación urbana $e$ industrial ${ }^{3}$ y la intervención activa del Estado, flanqueado por sectores medios y activos de creciente influencia política ${ }^{4}$. Pero son menos los trabajos que analizan los eslabones cruciales existentes entre la estructura económica y el desarrollo financiero interno ${ }^{5}$. Esta negligencia se da aun a sabiendas de la importancia que tuvo el crédito nacional y extranjero en el auge del crecimiento encabezado por la exportación, y la lucha de los nativos, a menudo subvalorada, pero estratégica, por controlar y dirigir las estructuras económicas latinoamericanas.

El estado actual de las investigaciones requiere contribuciones al debate sobre los efectos y las limitaciones del modelo exportador desde el punto de vista financiero. El presente artículo considera la evolución de uno de los sistemas financieros sudamericanos, influido por las fluctuantes necesidades de su producción agraria de exportación, y el comercio y la élite agrarias. Entre 1884 y 1950, el azúcar y el algodón tuvieron una importante participación de hasta el $72 \%$ del valor exportador peruano. Estos productos agrarios de exportación dieron un alto valor de rendimiento y fueron la base de las actividades financieras y económicas de los capitalistas peruanos ${ }^{6}$.

Para descubrir las conexiones concretas entre el modelo exportador peruano y su superestructura financiera, calcularé en primer lugar el nivel del desarrollo financiero peruano en relación con la producción y riqueza nacional y con otros países más y menos desarrollados. Sobre esta base, intentaré después dar respuesta a la cuestión de si la estructura financiera del Perú pudo afrontar el desafio del crecimiento y el desarrollo ${ }^{7}$. De esta forma valoraré si la estructura financiera peruana: 1) facilitó o no la diversificación productiva y autónoma dentro del sector exportador agrario y más allá, y 2) si contri-

1 Cortés Conde y Hunt (1985), Bergquist (1979), Weaver (1977), Klarén y Bossert (1986).

2 Coatsworth (1981).

3 Cariola y Sunkel (1985), Weaver (1980).

- Topik (1987), Bergquist (1986), Albert (1988).

5 A excepción de Marichal (1988) y Drake (1989).

- El valor de rendimiento se define como la inversión o reinversión de beneficios en insumo y mano de obra local: Thorp y Bertram (1977), pp. 40, 153; The West Coast Leader (WCL), vol. 15 , núm. 788,22 marzo de 1927 , p. 9.

7 Morris (1984). 
buyó o no a una mejor distribución social y regional de la renta por medio de una adecuada adjudicación y distribución del crédito ${ }^{8}$.

Según los índices que miden la evolución cuantitativa de los activos bancarios, y el volumen de los activos financieros totales en relación con la producción y riqueza nacional ${ }^{9}$, podemos establecer que entre 1885 y 1965 hubo en Perú un desarrollo financiero, extremadamente fluctuante, pero en general positivo. Si se interpolan mis estimaciones para la ratio anterior a 1965 de instrumentos financieros/producto nacional bruto (PNB), con medidas más contemporáneas ${ }^{10}$, como se hace en la tabla $I$, se observa una considerable subida desde 1960 hasta 1965, análoga, aunque más pronunciada, a la que se produjo entre 1935 y 1945.

\section{TABLA I}

Indices de desarrollo financiero

Diversos paises, 1850-1965

\begin{tabular}{|c|c|c|c|c|c|c|c|}
\hline \multirow{2}{*}{ AÑOS } & \multicolumn{4}{|c|}{ Total activos financieros/PNB } & \multicolumn{3}{|c|}{$\begin{array}{l}\text { Ratio de interrelaciones } \\
\text { financieras, FIR }\end{array}$} \\
\hline & PERU & MEXICO & EE.UU. & G. BRETAÑA & MEXICO & INDIA & EE.UU. \\
\hline $1850 \ldots \ldots$ & & & 1,33 & 4,95 & & 0,64 & 0,47 \\
\hline $1875 \ldots \ldots$ & 0,59 & & 2,29 & 3,44 & & 0,47 & 0,64 \\
\hline $1885 \ldots \ldots$ & & & & & & & \\
\hline $1895 \ldots \ldots$ & & 0,27 & 4,61 & 6,41 & & 0,40 & 0,71 \\
\hline $1905 \ldots \ldots$ & 0,44 & 0,38 & & & & & \\
\hline $1910 \ldots \ldots$ & 0,65 & 0,52 & & & & & \\
\hline $1914 \ldots \ldots$ & 0,74 & & 3,47 & 5,70 & & 0,34 & 0,83 \\
\hline $1925 \ldots \ldots$ & 0,68 & & & & 0,36 & 0,30 & 1,29 \\
\hline $1929 \ldots \ldots$ & 0,56 & 1,03 & 5,61 & $\begin{array}{l}6,96 \\
7,54\end{array}$ & 0,64 & 0,38 & $\begin{array}{l}1,27 \\
1,32\end{array}$ \\
\hline $1939 \ldots .$. & 0,74 & 1,55 & 5,17 & $\begin{array}{l}7,54 \\
5,71\end{array}$ & 0,74 & 0,45 & 1,17 \\
\hline $1950 \ldots .$. & 0,59 & 1,33 & 3,90 & 5,71 & & & \\
\hline $1960 \ldots .$. & 0,78 & & & 4,77 & 0,68 & 0,57 & 1,28 \\
\hline $1965 \ldots .$. & 1,72 & 1,48 & 4,42 & & & & \\
\hline
\end{tabular}

8 Goldsmith (1969), Mckinnon (1973), Leff (1976), Reynolds (1973).

9 Goldsmith (1985), pp. 2, 44 (1987), pp. 1-9.

10 Reynolds (1973), pp. 68-70 basado en mediciones para el año 1965 en Cobo del Prado y Garrido Lecca (1972). Véase también Thorp (1972). 


\begin{tabular}{|c|c|c|c|c|c|c|c|c|c|c|}
\hline \multirow{3}{*}{ AÑOS } & \multicolumn{3}{|c|}{ Activos bancarios/exportaciones } & \multicolumn{7}{|c|}{ N.o de entidades bancarias } \\
\hline & \multirow[t]{2}{*}{ PERU } & \multirow[t]{2}{*}{ COLOMBIA } & \multirow[t]{2}{*}{ MEXICO } & \multicolumn{2}{|c|}{ PERU } & \multicolumn{2}{|c|}{ COLOMBIA } & \multicolumn{2}{|c|}{ MEXICO } & \multirow{2}{*}{$\begin{array}{c}\text { EE. UU } \\
\text { A }\end{array}$} \\
\hline & & & & A & B & A & B & A & B & \\
\hline \multicolumn{11}{|l|}{$1850 \ldots \ldots$} \\
\hline $1875 \ldots \ldots$ & & & & 16 & & & & & & \\
\hline $1885 \ldots \ldots$ & 0,23 & & & 3 & & & & 10 & & \\
\hline $1895 \ldots \ldots$ & 1,14 & & 0,99 & 4 & 5 & & & & & \\
\hline $1905 \ldots \ldots$ & 0,93 & & 1,42 & 6 & 12 & & & 35 & 63 & \\
\hline $1910 \ldots \ldots$ & 1,15 & & 3,56 & 6 & 14 & & & & & 24514 \\
\hline $1914 \ldots \ldots$ & 1,55 & & & 7 & 21 & 14 & & & & \\
\hline $1925 \ldots \ldots$ & 1,87 & 1,09 & 0,85 & 12 & 28 & 35 & & 76 & 66 & \\
\hline $1929 \ldots \ldots$ & 1,43 & 1,97 & & 15 & 36 & 16 & & & & 23.719 \\
\hline $1939 \ldots .$. & 2,52 & 1,80 & 1,42 & 13 & 87 & & & 124 & 61 & 14.534 \\
\hline $1950 \ldots \ldots$ & 2,15 & & 1,83 & 16 & 184 & 14 & 171 & 414 & 846 & 14.146 \\
\hline $1960 \ldots \ldots$ & 2,17 & & 3,60 & 30 & 658 & 18 & 522 & 462 & 2.346 & 13.472 \\
\hline $1965 \ldots \ldots$ & & & & 30 & 688 & & & 461 & 3.108 & 13.600 \\
\hline
\end{tabular}

Notas: $A=$ número de oficinas principales

$B=$ número de oficinas secundarias y agencias

Fuentes: Para Perú, estimaciones basadas en Camprubi (1957), p. 119, 217; Extracto y Anuario estadistico del Perí (1919-1966); Boloña (1981); Banco Central de Reserva, Cwentas nacionales del Perí (Lima 1960-1974) y Memoria (Lima, 1972-1973); Superintendencia de Bancos, Memoria y estadistica bancaria (Lima, 1931-1969); Quiroz (1986); Reynolds (1973), pp. 68-70; Lough (1915), p. 66.

Los indices de activos financieros sobre PNB e Interrelaciones Financieras para México, EE.UU., Gran Bretaña e India de Goldsmith (1985), cuadro 19. Sobre instituciones financieras norteamericanas ver Rose (1987), cuadro 1.3. Para México, Goldsmith (1966), cuadros 14 y 15; Solis (1970), cuadro iii.2; Cordero (1976), cuadro 1; Ramirez (1985), cuadros 1, 35 y 39; José A. Bátiz, eTrayectoria de la banca en México hasta 1810w, en Ludlow y Marichal (1986), pp. 267-297; Moore (1963), cuadro 2. Nacional Financiera S. A., Statistics on Mexico (México, 1977), cuadros 7.3, 6.1; Solis y Brothers (1966), cuadros i.a, ii.b.

Para Colombia, Jorge Rodriguez y William McGreevey (1970); Basch (1966); Bravo Holguín (1966); Drake (1989).

El desarrollo financiero a largo plazo evidentemente no se mantuvo según la ratio de activos financieros/PNB. Es posible que este indice no exprese adecuadamente el desarrollo financiero, si por ejemplo se da un repentino descenso del denominador PNB (debido a una baja repentina en las exportaciones), o si los activos financieros se inflan por una excesiva especulación o por falta de oportunidades de asignación del crédito productivo. Por tanto, es necesario estudiar el Ratio de Interrelaciones Financieras (RIF, ratio de activos financieros/activos tangibles), que es más preciso, y analizar con detalle las fluctuaciones y fases de desarrollo de una estructura financiera concreta. 
Pero todavía no es posible hacer una aproximación exacta del RIF peruano, por falta de datos estadísticos sobre la riqueza nacional. De todas formas se pueden identificar tres ciclos muy claros en el desarrollo financiero del Perú, analizando los datos disponibles sobre los activos financieros del sector bancario. Estos incluyen los periodos de 1895-1915, 1916-1932 y 19331950. La evolución de los activos sociales de los bancos comerciales y de ahorro, los depósitos y créditos que se muestran en la figura 1, describe estas fases con una tendencia general al alza. Más adelante intentaré explicar los factores y agentes que afectan a estas fluctuaciones.

Comparado con el desarrollo financiero de México, el del Perú es más modesto (aproximadamente la mitad que el de México si se mide por la ratio de activos financieros/PNB para 1929-1960), así como menos abrupto en sus oscilaciones. La estimación aproximada de la ratio peruano para 1905 y 1910 es ligeramente superior a la de México en los mismos años; sin embargo, México se mantiene muy por delante en la proporción de los activos bancarios con las exportaciones en los mismos años. La ventaja desaparece en este último indice y Perú se pone en cabeza entre 1925 y 1950. Según los especialistas, México atravesó una verdadera revolución financiera desde 1939, después de experimentar un fuerte descenso y un pobre rendimiento entre 1910 y 193811.

El desarrollo financiero del Perú se acerca más e incluso es marginalmente superior al de Colombia, si observamos la evolución en el número de instituciones bancarias y la ratio de activos bancarios/exportaciones entre 1914 y 1950. Para los años 1965-1969 las ratios colombiano y brasileño de activos financieros/PNB son, por término medio, respectivamente sólo cuatro quintas partes y dos tercios del peruano ${ }^{12}$.

Con respecto a las economías desarrolladas, la ratio peruano de activos financieros/PNB se queda claramente atrás: la quinta y octava parte del de Estados Unidos y Gran Bretaña respectivamente en 1875 y 1914, la décima y la duodécima en 1929, y la séptima y la décima a partir de 1939.

En general, Perú, México y la India no tienen un aumento rápido y sostenido de sus ratios activos financieros/PNB y RIF como el que exhibieron los Estados Unidos entre 1850 y 1913. Ni las ratios de los países más pobres permanecen constantemente altos después de 1914, como en los Estados Unidos. Asimismo, la expansión de los bancos principales en Perú, Colombia y México, es inverso al número decreciente de instituciones bancarias en el

11 Goldsmith (1966), Solis y Hermanos (1976).

12 Reynolds (1973), p. 70. 
racionalizado sistema bancario estadounidense desde 1930. Esto probablemente se debe al creciente número de bancos regionales y de desarrollo y a la intervención financiera del Estado en Latinoamérica. Sin embargo, la expansión de las sucursales bancarias es común a los cuatro países después de 1940, sobre todo en los casos de México y EE. UU.

Según esta breve ojeada comparativa, no se puede calificar de «sustancial» la evolución financiera del Perú, como la de México en la década de 1960 , como concluyó Goldsmith ${ }^{13}$. La posición del Perú en el desarrollo financiero de América Latina puede calificarse de intermedia y superior a la de otros países de tamaño similar, como Colombia. Comparadas con las estructuras financieras desarrolladas, la peruana es, sin embargo, muy limitada en su evolución.

A pesar de los resultados relativamente modestos del desarrollo financiero del Perú, no se pueden silenciar los logros históricos que quedan difuminados por la pesimista opinión de que los costes del modelo financiero exportador fueron superiores a los beneficios ${ }^{14}$. Ni siquiera a la estructura financiera del Perú le faltaron efectos positivos sobre su estructura económica que a veces se pasan por alto. Tampoco las instituciones y la élite financiera del Perú pueden tacharse simplemente de pro extranjeras. Las pruebas apuntan a unas complejas relaciones con los intereses financieros extranjeros, así como a sus relativamente autónomas manipulaciones financieras en ciertos episodios históricos. En este aspecto el momento es crucial y debe analizarse en una valoración general de los hechos históricos.

El período 1884-1950 fue determinante para la formación de la moderna economía capitalista del Perú. Esto no fue pequeña hazaña, porque requirió tres grandes reajustes estructurales que aumentaron la concentración económica y financiera: el primero, después de la destructiva guerra con Chile de 1879-1883, el segundo después de los efectos iniciales de la Primera Guerra Mundial, y el tercero después de la depresión de 1929-1932. Perú no estaba al margen de los cambios económicos del mundo, y su estructura financiera - como la de todos los países en la creciente economía del mercado mundial- sufrió pronto el impacto de los desgarros monetarios internacionales y organizativos ${ }^{15}$.

13 Goldsmith (1966), p. 15.

14 Malpica (1977), p. 23; Diez Canseco (1960), Pp. 12-15; Yepes (1972), Pp. 158-164.

15 Albert (1988), pp. 37-38. 
Estos profundos reajustes pusieron en juego cuatro agentes básicos y competitivos en el proceso de intermediación y flujo de fondos en la economía peruana de exportación: los agroexportadores nativos con su diversa capacidad autónoma y empresarial para el ahorro y la recepción de créditos; los acreedores e inversores extranjeros, sobre todo los comerciantes importadores extranjeros que buscaban consolidar sus garantias prendarias y beneficios como prestamistas a un país escaso de capital; las autoridades monetarias y bancarias locales que mediaron en los periódicos conflictos de intereses entre productores, comerciantes y acreedores en lo que se refiere al patrón oro, la estabilidad monetaria y la adjudicación de créditos, y, por último, el mayor papel del Estado en la reglamentación financiera interna y su recurso al endeudamiento con el exterior.

En los primeros años que siguieron a la Guerra del Pacífico se observa una aparente discontinuidad en la conexión entre el campo financiero interior y la actividad exportadora. El legado de los fracasados bancos de emisión y las hipotecas agrarias a largo plazo durante la Era del Guano (1862-1879) ${ }^{16}$, y una desconfianza muy difundida hacia la economía local, la situación monetaria y la deuda pública, determinaron que las transacciones bancarias se mantuvieran estrictamente comerciales a corto plazo y adversas al crédito agrario. Los principales bancos de préstamo comercial y depósito, cada vez más dominantes, rechazaban de plano las emisones de papel moneda. No existian instituciones financieras públicas ${ }^{17}$. En el año 1890 se llegó a un costoso acuerdo con los acreedores extranjeros para resolver la deuda impagada de $1876^{18}$.

Hasta la Primera Guerra Mundial el debilitado sector exportador dependió de las pocas casas fuertes o poderosas empresas comerciales, la mayoría extranjeras, que concedian costosos créditos comerciales a los plantadores de azúcar y algodón ${ }^{19}$. Los productores agrarios siguieron siendo básicamente nativos, debido en parte a la falta de interés del capital comercial extranjero por asumir los riesgos de un control directo sobre la producción para la exportación ${ }^{20}$. Los terratenientes costeros, con buenas relaciones comerciales y acreedores hipotecarios privados, concentraron las tierras de los propieta-

16 Camprubi (1957), Hunt (1985).

17 Quiroz (1986), p. 40.

18 Miller (1976).

19 Harvey (1936), p. 570.

20 Michael Grace a A. Leslie, 17 de abril de 1884, W. R. Grace \& Co. Papers, Columbia University Library, New York, Box 58, núm. 155, p. 292. 
rios tradicionales incapaces de pagar sus deudas ${ }^{21}$. Así, en 1900, cuando los precios internacionales del azúcar y el algodón habían mejorado (atrayendo una renovada inversión en la agricultura comercial), los plantadores nativos estaban endeudados con los acreedores comerciales extranjeros y dependían financieramente de ellos ${ }^{22}$. Los agroexportadores insatisfechos formularon protestas por la falta de instituciones adecuadas de crédito agrario. Ya en 1902 propusieron la creación de un banco agrario y otras formas de crédito agrario 23 . Hasta 1931, este banco no se hizo realidad operativa.

Los agroexportadores se opusieron inicialmente a la introducción del patrón oro. Preferian que continuara el sistema monetario basado en la plata. En la década de 1890 el precio internacional de la plata descendió ${ }^{24}$. De modo que los agro-exportadores se vieron favorecidos como recipientes de moneda extranjera de oro y deudores de moneda de plata. Cuando los proveedores de fondos y servicios comerciales exigieron su pago en oro, y la estabilización económica con el predominio del oro permitió una proletarización menos costosa de la región agraria costera, fueron retirando gradualmente su oposición al patrón oro 25 .

En las cuestiones de política monetaria prevalecieron los intereses de los bancos locales, los acreedores y los comerciantes extranjeros. Entre 1898 y 1902 presionaron por la adopción de una rígida moneda de oro para ofrecer garantias y atraer al capital extranjero. Estas condiciones no se daban, por la inestable situación económica y fiscal ${ }^{26}$.

En esta fase los bancos comerciales preferían conceder créditos a los comerciantes y no a los plantadores. Los bancos evitaban la competencia directa con el negocio de crédito exportador de las firmas mercantiles. Los financieros nacionales establecieron una provechosa colaboración con el capital extranjero, que hizo florecer el negocio oligopolístico. La suscripción de títulos valores financiados en el extranjero y la importación de capitales extranjeros para financiar las acciones y obligaciones locales se pusieron de

21 Klarén (1973), pp. 5-12; contratos de mutuo c hipoteca, escribano Carlos Sotomayor, vols. 777-783, años 1881-1889, Archivo General de la Nacional, Lima.

22 Gonzales (1985), pp. 27, 33-35; Klinge (1945), pp. 73-75.

23 Aspillaga, Garland y Leguía (1902); Ramirez Gastón (1904) y (1964); «El Banco Agricola del Perún en El Economista Peruano, vol. 3, núm. 36 (febrero), p. 420.

24 Meller (1932).

25 Aspilllaga, Dubois y Gildemeister (1892); Correa y Santiago y Payán (1892); Banco del Callao, "Actas de reuniones del directorio», 30 de septiembre de 1892, vol. s, núm. 610, p. 251 en Archivo del Banco del Perú y Londres en Liquidación, Lima (BPLS).

26 Payán (1892), Garland (1908), Zabludowski (1984). 
moda entre 1898 y 1914 cuando el patrón oro estaba en plena operación ${ }^{27}$. Como resultado de las mejoras en la especialización institucional bajo el patrón oro, los tipos de interés para el crédito comercial e hipotecario descendieron.

Por el origen nacional de los directores y accionistas, se pueden distinguir tres tipos de bancos en este periodo: extranjeros, nativos y de residentes extranjeros. Las sucursales de los bancos extranjeros tenían un apalancamiento limitado en los asuntos internos por la fuerte representación nativa del sector financiero y la resistencia de los extranjeros a invertir en las finanzas peruanas después de la Guerra del Pacífico. Con excepción del intento temporal de un banco alemán y un banco americano por controlar la financiación de la exportación en la década de 1910, las sucursales de los bancos extranjeros se concentraron más bien en operaciones de cambio y transferencias internacionales.

Los bancos peruanos tenían a su cargo la liquidación de muchos deudores nacionales. Estos bancos también jugaron un papel crucial en el restablecimiento de una base legal para el crédito hipotecario, indispensable para la reconstrucción y restauración urbana después de la Guerra del Pacifico. Después de 1889 crearon los originales y prometedores créditos hipotecarios urbanos que sustituyeron a los créditos hipotecarios agrarios de la Era del Guano. Los financieros locales fundaron también compañías aseguradoras que pudieron controlar el campo de los seguros cuando las compañias extranjeras pusieron fin a sus operaciones en el Perú, como reacción a una legislación que exigia garantías en activos y propiedades locales 28 .

En 1900 las entidades bancarias peruanas controlaban el $82 \%$ del activo bancario total del Perú (véase Tabla II) debido a la fusión del Banco del Callao con la sucursal del London Bank of Mexico \& South America en una proporción de 3:2 a favor del capital peruano. Pero en 1921 y 1929 los peruanos controlaban respectivamente el $39 \%$ y el $32 \%$ de los activos bancarios totales, por la creciente importancia de los activos extranjeros y de residentes extranjeros ${ }^{29}$.

La categoria de banco de residentes extranjeros sólo tenia aplicación a un banco italiano. Comenzó como una entidad que básicamente concedía crédito

27 Godoy (1890-1897); Bolsa Comercial de Lima (1900-1914); sobre aspectos teóricos, véase Ford (1983), pp. 16-17, y Ford (1985), pp. 141-165.

28 Primera ley de compañias de seguros, artículos 4 y 5 en El Economista, vol. 1, núm. 16 (diciembre 1895); Inspección Fiscal de Compañias de Seguros (1903), pp. 116-119. Sin embargo, las compañias nacionales continuaron reasegurando en el exterior.

29 Quiroz (1986), pp. 48-56. 


\section{TABLA II}

Participación del mercado bancario comercial y de aborros peruano, por intereses nacionales, $1885-1965$

\begin{tabular}{|c|c|c|c|c|c|c|c|c|c|c|c|c|}
\hline \multirow[t]{2}{*}{$A \tilde{N} O S$} & \multicolumn{4}{|c|}{$N \cdot$ de bancos } & \multicolumn{4}{|c|}{$\begin{array}{c}\text { Porcentajes } \\
\text { de activos totales }\end{array}$} & \multicolumn{4}{|c|}{$\begin{array}{l}\text { Beneficios netos/ } \\
\text { capital y reservas }\end{array}$} \\
\hline & Nat. & Res. & Ext. & (Tot) & Nat. & Res. & Ext. & (Tot) & Nat. & Res. & Ext. & Todos \\
\hline $1885 \ldots \ldots$ & 2 & 0 & 1 & (3) & 55 & 0 & 45 & 100 & - & - & - & - \\
\hline $1895 \ldots \ldots$ & 6 & 2 & 1 & (9) & 62 & 24 & 26 & 100 & 0,06 & - & - & - \\
\hline $1900 \ldots \ldots$ & 11 & 3 & 0 & (14) & 82 & 18 & 0 & 100 & 0,09 & - & - & - \\
\hline $1905 \ldots \ldots$ & 15 & 3 & 0 & (18) & 65 & 24 & 11 & 100 & 0,11 & 0,11 & 0,05 & 0,10 \\
\hline $1915 \ldots \ldots$ & 19 & 5 & 3 & (27) & 58 & 17 & 25 & 100 & 0,04 & 0,01 & - & - \\
\hline $1925 \ldots \ldots$ & 21 & 6 & 12 & (39) & 38 & 32 & 30 & 100 & 0,15 & 0,17 & 0,05 & 0,13 \\
\hline $1935 \ldots \ldots$ & 5 & 27 & 5 & (37) & 26 & 45 & 29 & 100 & - & - & - & 0,08 \\
\hline $1945 \ldots \ldots$ & 147 & - & 3 & $(150)$ & $92 *$ & - & 8 & 100 & - & - & - & 0,15 \\
\hline $1955 \ldots \ldots$ & 269 & - & 3 & $(272)$ & $95^{* *}$ & - & 5 & 100 & - & - & - & 0,12 \\
\hline $1965 \ldots \ldots$ & 682 & - & 6 & (688) & 95 ** & - & 5 & 100 & - & - & - & 0,09 \\
\hline
\end{tabular}

Nota: Nat. = bancos nativos; Res. = bancos de residentes extranjeros; Ext. = bancos extranjeros; tot. = total; todos $=$ todos los bancos.

* En 1941 el Banco Italiano cambia su nombre por Banco de Crédito, y es considerado una institución nacional, pero sigue dominando el capital italiano y suizo francesa.

** El Banco Continental y otros bancos nativos permiten la participación estadounidense y

FUENTES: Inspección Fiscal de Bancos, Informe (Lima, 1921-1930); balances de instituciones; Quiroz (1986), 432-439; Cisneros (1912) Superintendencia de Bancos, Memoria (19311966) y Sitwación de las empresas bancarias (1931-1966).

italiano a la comunidad italiana del Perú, y más tarde evolucionó para convertirse en un banco competitivo local, con una participación en aumento en el mercado bancario nacional.

La supremacía bancaria peruana en este período era ejercida por el banco nacional más importante, el Banco del Perú y Londres (BPyL), que absorbió capital británico y francés entre 1897 y 1914 en busca del predominio oligopolístico; esto puso en peligro su carácter nativo ${ }^{30}$. Entre 1906 y 1920 los directores y accionistas extranjeros constituian aproximadamente las dos

30 Para establecer interesantes comparaciones entre el BPyL y el Banco Nacional de México, respectivamente las instituciones bancarias líderes en ambos paises para el. periodo 1884-1910, véase Ludlow y Marichal (1986), p. 258. 
terceras partes de los cuerpos decisorios del banco ${ }^{31}$. Los otros bancos peruanos, el Banco Internacional y el Banco Popular, actuaban como proveedores de crédito para los grupos de élite o las redes empresariales diversificadas en evolución.

Los intereses oligopolisticos y los bancos se resistian a aceptar la intervención estatal más allá de ciertos límites. Entre 1884 y 1919 las finanzas estatales se apoyaban considerablemente en el crédito comercial local, of reciendo la concesión de empresas recaudadoras de impuestos semipúblicas a intereses financieros privados. La deuda pública extranjera se había reducido drásticamente desde 1879. Sin embargo, la financiación extranjera de las acciones de compañías semipúblicas y los créditos limitados al Estado comenzaron a aumentar entre 1905 y 1914.

En lo que se refiere a la legislación, el Estado se limitaba a facilitar la circulación del oro, a emitir billetes según el patrón oro durante la Primera Guerra Mundial, a conceder privilegios monopolísticos a sus acreedores nacionales y a supervisar de forma limitada las secciones hipotecarias de los bancos, las compañias de seguros y las cajas de ahorros ${ }^{32}$. La insuficiente legislación estatal no pudo impedir los efectos negativos del crédito y la concentración de riqueza.

El escenario de capitalismo competitivo que se desarrollaba en Perú tenía sus inconvenientes al nivel social. En primer lugar, la concentración de riqueza entre unos pocos tuvo grandes consecuencias. Las entidades financieras y los grupos de élite concedian poco crédito a la clase popular. El sistema financiero peruano no estaba diseñado para ejercer un mayor impacto social. Puesto que los bancos comerciales no aceptaban pequeñas cantidades como depósitos, los pequeños ahorradores de Lima tenían que confiar en la Caja de Ahorros, que era regida por una institución benéfica. No se concedian créditos a estos pequeños ahorradores y los intereses sobre sus depósitos eran más bajos que los que obtenían los clientes de los bancos ${ }^{33}$. Los asalariados debían cubrir sus necesidades económicas empeñando sus bienes personales o sus salarios semanales, con un fuerte interés, a las muchas casas de préstamo activas que existían, la mayoría propiedad de extranjeros, sobre todo italianos. La falta de interés de los bancos comerciales por el negocio del pequeño ahorro y el préstamo, hasta finales de la década de 1920, dio lugar a breves

31 PByL, «Actas de Juntas de Accionistas», 26 diciembre 1906 y 18 marzo de 1907, vol. 2, pp. 58-62, BPLS.

32 Perú, Cámara de Diputados (1921), Quiroz (1986), p. 58.

33 Beneficencia Pública de Lima (1909-1929), Mayer (1906), p. 1155; Camprubi (1968), pp. 86-88. 
intentos de combatir la usura por parte de la Iglesia, que abrió montes de piedad de estilo colonial ${ }^{34}$.

En segundo lugar, el centralismo financiero de Lima se hizo abrumador. El establecimiento de sucursales bancarias en provincias se retrasó considerablemente. La estructura bancaria peruana no cubrió toda la geografia nacional hasta 1910. Sin embargo, las sucursales situadas en las ciudades de provincia se limitaban a ser «agencias para el descuento de instrumentos comerciales y la compraventa de letras de cambio en Limam. ${ }^{36}$. Sus clientes en provincias eran básicamente rentistas tradicionales, $y$ en los años 30 las cuentas deudoras eran sobre todo de comerciantes ${ }^{36}$.

La construcción de nuevas carreteras y el despertar de algunos intereses industriales en las regiones del interior desde los años 20 aumentaron el interés de los bancos y los grupos de élite en el aspecto regional. Pero como vemos en la tabla III, siguió prevaleciendo la tendencia a concentrar los créditos en Lima y en las regiones costeras. Los préstamos hipotecarios concedidos en provincias fuera de Lima constituían en 1915 sólo de un 17 a un 23 por 100 del total nacional. En 1926 los depósitos procedentes de provincias sumaban sólo el $28 \%$ de los depósitos situados en los bancos comerciales. El Estado patrocinó bancos de desarrollo que aparecieron en 1931 e hicieron poco por alterar esta situación. Además, los grupos dirigentes provinciales tardaron más que los grupos costeros en superar su especialización comercial.

A pesar de la falta de un sistema financiero nacional equilibrado, entre los años 1917 y 1929 se logró un avance significativo hacia una relativa independencia económica de la influencia extranjera. En este período la élite consiguió transformar los beneficios de un floreciente ciclo exportador (con fuertes variaciones de los precios a corto plazo) en una independencia temporal de los acreedores extranjeros del sector privado. Durante la Primera Guerra Mundial y después los inversores extranjeros, especialmente los británicos y franceses, retiraron gran parte de sus inversiones en Perú por la situación de

34 Inspección de Casas de Préstamo, «Relación de las casas de préstamo que actualmente existen en la capital», en Boletin Municipal (Lima), primer semestre de 1901, Pp. 37, 69; «Parte mensualw, ibid., 1889-1913; Olivares (1923).

35 Harvey (1936), pp. 566-457.

36 BPyL en liquidación, «Registro de créditos inscritos por oficinas» y «Registro de créditos no inscritos por oficinas", mayo de 1931, BPLS.

37 Mallon (1983), p. 273; Roberts (1976), p. 155; Tamayo Herrera (1981), p. 130. 
TABLA III

Indicadores de la concentración bancaria regional peruana, 1894-1965

\begin{tabular}{|c|c|c|c|c|c|c|c|c|c|c|}
\hline \multirow[t]{2}{*}{$A \tilde{N} O S$} & \multicolumn{3}{|c|}{$\begin{array}{l}\text { Tadas las provincias } \\
\text { (Lima excluida) }\end{array}$} & \multicolumn{3}{|c|}{$\begin{array}{l}\text { Créditos } \\
\text { comerciales }\end{array}$} & \multicolumn{4}{|c|}{$\begin{array}{c}\text { Créditos } \\
\text { del Banco Industrial }\end{array}$} \\
\hline & Cred. com & Dep. com. & Hipotecas & Costa & Sierra & Selva & Prov. & Costa & Sierra & Selva \\
\hline $1894 \ldots$ & & & 23 & & & & & & & \\
\hline $1905 \ldots$ & & & 22 & & & & & & & \\
\hline $1915 \ldots$ & & & 17 & & & & & & & \\
\hline $1926 \ldots$ & & 28 & & & & & & & & \\
\hline $1935 \ldots$ & 17 & 19 & & & & & & & & \\
\hline $1945 \ldots$ & 28 & 28 & 22 & 90 & 9 & 1 & 27 & 87 & 11 & 2 \\
\hline $1955 \ldots$ & 19 & 21 & 6 & 93 & 6 & 1 & 27 & & & \\
\hline $1965 \ldots$ & 21 & 23 & 2 & 92 & 7 & 2 & 51 & 70 & 29 & 1 \\
\hline
\end{tabular}

Nota: Cred. = créditos; Com. = comerciales; Dep. = depósitos; Prov. = Provincias

Fuentes: Inspección Fiscal de Bancos Hipotecarios, Memoria (1902-1907); «Banco del Perú y Londres, Sección Hipotecaria, Distribución de préstamosw, El Comercio (1894-1901); Inspección Fiscal de Bancos, Memoria (1931-1966); Anwario estadístico (1955, 1966).

guerra y la recesión internacional de postguerra. Los capitalistas nativos llenaron el vacio con presteza. Con entusiasta impulso, los peruanos se hicieron con los complejos agro-industriales y las instituciones bancarias ${ }^{38}$.

Por primera vez desde la Era del Guano, la élite agraria peruana por fin controlaba y coordinaba el núcleo de la financiación del sector exportador agrario. Esto no debe olvidarse, a pesar de la continuada presencia de compañías mineras, petroliferas y de ferrocarriles americanas y británicas (Cerro de Pasco, Vanadium, Northern Perú Mining, International Petroleum, Lobitos Oilfields, Peruvian Corporation) que para los años 20 habían consolidado su control sobre la mayor parte de las exportaciones de mineral ${ }^{39}$.

Los beneficios por la exportación se habian disparado entre 1917 y 1920 , y por tanto habían aportado una relativa independencia fiscal a la Patria Nueva del presidente Augusto B. Leguia (1919-1930). Además, se aumentó la

38 El control de los accionistas franceses y británicos del BPyL descendió del $73 \%$ del total de acciones en 1913, a un $34 \%$ en 1921, "Accionistas», 1913-1921, BPLS. Los complejos agroindustriales de Santa Bárbara, Puente Piedra, Paramonga y San Nicolás fueron adquiridos o capitalizados por nacionales en los años 1917-1921, Informaciones Mercantiles e Industriales (1921), Albert (1976), p. 1402; Basadre (1968), vol. IX, p. 300.

39 Thorp y Bertram (1978), cap. 5; Dore (1988), cap. 4. 
protección arancelaria para incentivar a la industria nacional. La construcción de carreteras, los programas de regadío, el crecimiento urbano y una variedad de mejoras públicas, constituyeron los pilares de la política económica de desarrollo del presidente Leguía ${ }^{40}$.

En 1920-1922 se negoció en unas dificiles conversaciones con la élite financiera, que se oponía a la introducción de un banco de reservas, una mayor intervención del estado en cuestiones económicas y financieras. Leguía ofreció a cambio flexibilidad crediticia a los intereses financieros nacionales relacionados con el sector agrario de exportación. Nombró a su familiar Eulogio Romero, presidente del nuevo Banco de Reservas en 1922. Romero fue sustituido en 1925 por el plantador de azúcar y acreedor del Estado Augusto Gildemeister, el ex vicepresidente del banco. Eulogio Fernandini, un importante minero, fue también uno de los directores del banco nombrados por el Estado. Los agroexportadores y mineros mantuvieron así una presencia estratégica en el banco. Los bancos locales, no el Estado, facilitaron el capital para el banco ${ }^{41}$.

El Banco de Reserva hacia redescuentos a bancos peligrosamente hiperespecializados en el crédito a la agricultura comercial, por ejemplo los préstamos del BPyL al sector azucarero. Esto aumentó las posibilidades de una catástrofe financiera en el caso de que ocurriera una crisis en la exportación ${ }^{42}$. El Banco de Reserva de Leguía continuó con algunas modificaciones la política monetaria adoptada en Perú durante la crisis del oro de 1914. La moneda de oro había sido reemplazada por papel moneda emitido por los bancos privados y respaldado por reservas de oro en el extranjero. Leguía hizo prerrogativa del Estado este tipo modificado del patrón oro haciéndose con el control de las reservas de oro peruanas en Estados Unidos y transfiriéndolas provechosamente a Londres ${ }^{43}$. Leguía desplazó así los intereses de los bancos locales en la política monetaria. Garantizando la estabilidad monetaria a los acreedores extranjeros, añadía incentivos al crédito extranjero,

40 Leguia (1936); Hooper López (1964); críticas tendenciosas a Leguia en Ugarteche (1930), y Ramirez Gastón (1964), p. 39; Drake (1989), pp. 216-217.

41 Dejean de la Batic al Ministre des Affaires Etrangères, 6 de abril de 1922, Archive du Ministère de l'Economie et des Finances, Paris, B32-896; Poindexter al secretario de Estado, 29 de junio de 1925, Estados Unidos. Departamento de Estado, Estados Unidos. National Archives (USNA), Washington, D. C., microcopia 746, rollo núm. 22, 823.526/46.

42 Caja de Depósitos y Consignaciones (1925), núm. 39; Banco de Reserva del Perú (19221930); BPyL; «Directorio», 1921-1928, BPLS.

43 Presidente del National City Bank a Andrew W. Mellon, 1 junio 1921, U. S. Department of the Treasury, Box 162, File núm. 1, USNA; U. S. Department of State (1936), vol. II, pp. $663-$ 666. 
aunque con ello también disminuía las posibilidades de los agroexportadores para beneficiarse de las devaluaciones monetarias.

Los programas de obras públicas y el patrocinamiento de la élite requerian de Leguía grandes gastos presupuestarios. Gran parte de su estrategia política dependia de que no se vinieran abajo estos dos pilares, las obras públicas y el apoyo de la élite. La caída de los beneficios de la exportación en 1921-1922 y 1925-1926 amenazó con desequilibrar el presupuesto del Estado, con paralizar el programa de obras públicas y depreciar la moneda. Leguía recurrió al préstamo extranjero a gran escala.

Los 20 fueron años en que el crédito, público y privado, en aumento, financió la fiebre de la construcción de carreteras y compra de automóviles y camiones que cambió la faz de las comunicaciones terrestres peruanas 44 . Las obras de regadio, como Imperial y Cañete, fueron posibles gracias a un crédito estatal barato que subvencionó la compra de terrenos de regadio por pequeños plantadores de algodón ${ }^{45}$. Las obras de urbanización, saneamiento y pavimentación en Lima y las ciudades provinciales dieron un gran salto hacia adelante.

La política de los bancos americanos de conceder abundantes créditos a los gobiernos sudamericanos era parte de un movimiento en favor de los intereses estadounidenses, que acabaron con la supremacia financiera y comercial británica en países como el Perú. El ambiente financiero internacional era optimista. Los observadores extranjeros veían muy prometedor el futuro del Perú. Leguía comprendió pronto las ventajas de dar grandes «facilidades para la inversión del capital no empleado de los paises industrializadosn ${ }^{46}$.

Como consecuencia del aumento de la intervención estatal, las élites exigieron un gobierno que les respaldara, un incremento del crédito oficial y un suministro flexible de moneda que les resolviera los problemas financieros ligados a los descensos en la exportación. Pero los acreedores extranjeros también pretendian beneficiarse de la intervención estatal. Los bancos comerciales locales perdieron los prometedores mercados hipotecario y del pequeño ahorro, cuando el Estado se hizo con su control para aumentar su atractivo financiero ante los acreedores extranjeros. Además, los contratistas extranjeros redujeron los rendimientos de las obras públicas financiadas con fondos prestados. Los oligopolios industriales limitaban el campo de la financiación

4 Wilson (1987), p. 127.

45 Klinge (1935), p. 262.

46 anterview with President Leguias por John Clayton en Tbe West Caast Leador (WCL), vol. 16, núm. 842 (3 abril de 1927), p. 22; Stallings (1987). 
industrial. Por tanto, la hiperespecialización en crédito a la agricultura comercial siguió aumentando. Esto quedaba patente en la gran cantidad de redescuentos de documentos mercantiles ligados a las grandes propiedades, que realizó el Banco de Reserva ${ }^{47}$. En otras palabras, el Estado estaba contribuyendo a la infraestructura nacional, pero frenando las inversiones financieras locales.

Con la deposición de Leguía por un golpe de Estado militar en agosto de 1930 , la inestabilidad política, rasgo común en los paises sudamericanos durante los años de la depresión, intensificó la crisis económica del Perú. El crédito comercial privado se habia restringido desde noviembre de 1929; los cuentacorrentistas se dejaron llevar del pánico en octubre de 1930, obligando al BP y L a cerrar temporalmente. La depreciación monetaria continuó sin control, proporcionando algún alivio a los exportadores, pero causando la desolación entre los importadores y los deudores en moneda extranjera ${ }^{48}$. El crédito comercial directo a los intereses agrarios se vino abajo. Poco hicieron en 1930-31 los militares en el poder, que asistieron a la intensificación de las crisis de la exportación y las finanzas cuando los precios de exportación del cobre, el azúcar y el algodón cayeron verticalmente. Cumplieron su promesa de proceder en cuestiones económicas y financieras con «honrada parsimonia» 49.

Los intereses agroexportadores demostraron ser una relativa bendición en el período de recuperación económica que siguió a 1932. Por un lado, la producción de algodón, con grandes rendimientos y mejores precios desde 1933, suministró suficiente moneda extranjera para sostener las operaciones crediticias del Banco Central. Por otro lado, la bien organizada élite agraria demostró su influencia antidemocrática con la defensa de sus estrechos intereses a nivel político y financiero.

En lo más profundo de la depresión, el sector agrario tenia un respaldo financiero extremadamente precario. El SNA presentó a los gobiernos posteriores a Leguia largas listas de peticiones que iban desde precios más bajos para los fertilizantes, hasta la reducción de impuestos ${ }^{50}$. Se consideraba

\footnotetext{
47 Banco de Reserva, Memoria, 1922-1930.

48 WCL, vol. 18, núm. 965 (12 de agosto de 1930), p. 1.

49 WCL, vol. 18, núm. 967 (26 de agosto de 1930), p. 16.

so «Sociedad Nacional Agraria», WCL, vol. 18, núm. 974 (14 de octubre de 1930), p. 19; «El problema azucarerom, La Vida Agricola, vol. 14, núm. 158 (1937), pp. 35-38.
} 
opresivos a los babilitadores (prestamistas) comerciales particulares. Los intereses extranjeros amenazaban con apoderarse o embargar las propiedades agrarias de los peruanos que habian alcanzado una significativa autonomia financiera en el periodo anterior. Sin embargo, la demora en el proceso de liquidación de los activos y obligaciones del BPyL, y la devaluación monetaria, libraron de una quiebra desastrosa a importantes plantaciones.

Se presentaron al Congreso varios proyectos para que declarase una moratoria sobre préstamos hipotecarios privados e impusiera el pago de las deudas en moneda nacional ${ }^{51}$. El presidente militar, coronel Luis Sánchez Cerro, había seguido pagando la deuda externa en medio de la depresión económica general de 1930-1931. Hasta después de otros varios levantamientos desestabilizadores más, no se tomaron medidas sobre la candente cuestión de la deuda externa. Aconsejado por el plantador de azúcar norteño Rafael Larco Herrera, ministro de Asuntos Exteriores y posteriormente ministro de Finanzas, el gobierno provisional de compromiso de David Samanez Ocampo suspendió la devolución de la deuda exterior peruana el 20 de marzo de 1931 52. Este impago, que duró prácticamente hasta 1951, y el abandono del patrón oro en mayo de 1932, fueron esenciales para la recuperación económica y financiera y la supervivencia de los agroexportadores 53 .

El Banco Agrícola del Perú, un ambicionado proyecto de los agricultores, por fin se hizo realidad operatoria en 1931. El vacio dejado por el BP y L en la estructura del crédito agrario fue llenado en parte por el Banco Agricola, que fue el único en facilitar un crédito muy necesario a los plantadores de algodón y azúcar. La nueva institución se creó en agosto de 1931 como un retoño del Banco Central, reduciendo el capital de este último en favor del primero, en medio del mayor escepticismo en cuanto a una recuperación de la exportación agraria ${ }^{54}$.

El Banco Agrícola era la versión peruana de un «New Deal», en el que el influyente sector de los plantadores estaba encabezado por el SNA. Los fondos para el banco se extrajeron del capital del Banco Central a fin de

51 «Proposed Moratorium on Mortgage Loans», WCL, vol. 20, núm. 1051 (5 de abril de 1932) 2 «Obligations Contracted in Foreign Money. Lima Chamber of Commerce Voices its Protest Against Recent Legislation», WCL, vol. 20, núm. 1071 (23 de agosto de 1932), p. 4.

52 «Peruvian National Loans: Service Suspendend by Supreme Decree», WCL, vol. 19, núm. 997 (24 de marzo de 1931), p. 1.

53 «El cambion, La Vida Agrícola, vol. 13, núm. 146 (1936), pp. 21-24.

54 WCL, vol. 19, núm. 1018 (18 de agosto de 1931), p. 1; ibid., vol. 19, núm. 1027 (20 de octubre de 1931), p. 1. Pedro G. Beltrán, un importante agricultor, ocupó el puesto de vicepresidente del nuevo Banco Central de Reserva; Banco Central de Reserva, Boletín mensual, vol. 1, núm. 1 (septiembre de 1931). 
conceder a las propiedades más productivas mayores créditos a un tipo de interés más bajo. De esta forma, una importante porción de los escasos recursos financieros del Estado se sustrajo a la estabilización del tipo de cambio recomendada por el asesor financiero americano E. Kemmerer y se dedicó a la financiación del sector exportador agrario. En la década de 1930 los plantadores de algodón eran los principales beneficiarios de los préstamos «controlados» del Banco Agrícola: en 1932, por ejemplo, del total de sus préstamos (10.551.830 soles), el banco adjudicó el $66 \%$ al algodón, el 14,7\% al arroz, el 8,3\% a los productores de azúcar y el $8 \%$ a los ganaderos 55 .

La política crediticia del Banco Agrícola consiguió asegurar sus préstamos supervisando muy de cerca la capacidad empresarial del deudor y sus sistemas de contabilidad. Los préstamos se aplicaban básicamente a financiar las cosechas anuales y sólo se renovaban previo pago total de préstamos anteriores. El sector comercial agrario era el único que se beneficiaba de este sistema de crédito controlado, porque los costes de supervisión eran demasiado altos para ser aplicables a préstamos en pequeña escala.

Los pequeños agricultores recibieron sólo el $7,7 \%$ de los préstamos totales (263 millones de soles) entre 1931 y 1944. El banco veía un riesgo mayor en el préstamo a pequeños productores que aún no estaban organizados en cooperativas ${ }^{56}$. Hasta 1944 no se habia concedido ni un solo crédito a las comunidades campesinas, porque, como dijeron los directores del banco, los campesinos «no los habían solicitado" 57.

A cambio de patrocinar el Banco Agrícola, el Estado pudo obtener de los bancos comerciales y agrícolas una seric de letras de cambio extranjeras que adquiria y redescontaba el Banco Central. Esto dio un relativo respaldo a la moneda peruana, que no se siguió depreciando e incluso se estabilizó entre 1933 y 193858 .

Además, en 1932 un Préstamo Patriótico estimuló los préstamos internos y una mayor circulación. El primero de los subsiguientes préstamos privados

55 «Farmer's Bank of Perun, WCL, vol. 21, núm. 1092 (17 de enero de 1933), p. 25; «El Banco Agrícola y la Superintendencia de Bancosm, La Vida Agricola, vol. 12, núm. 139 (1935), pp. 439-441, y vol. 12, núm. 144 (1935), pp. 915-918.

36 Los pequeños agricultores recibieron un $12,8 \%$ de los préstamos del banco en 1944 . No se les otorgó préstamos entre 1931 y 1933, Saint Marie (1945), pp. 104-111; *Crédito agrícola: crédito para el pequeño agricultom, La Vida Agrícola, vol. 12, núm. 138 (1935), pp. 343-346; «Memoria del Banco Agrícola del Perú», ibíd., vol. 14, núm. 170 (1938), pp. 95-100.

57 Saint Marie (1945), p. 111; «La labor del Banco de Fomento Agropecuario del Perúm, La Crónica, 31 de mayo de 1959, pp. 10-11.

58 «Policy of Central Reserve Bank of Peruw, WCL, vol. 22, núm. 1172 (31 de julio de 1934), pp. 20-21, y «Monetary Policy of the Central Bankw, vol. 22, núm. 1191 (11 de diciembre de 1934), p. 7; Portocarrero (1983), pp. 37-38. 
fue concedido por el semifascista Sánchez Cerro para la compra de material de defensa con que afrontar la crisis fronteriza de Leticia con Colombia, que amenazaba con convertirse en otra Guerra del Chaco. Cuando el general Oscar Benavides subió al poder tras el asesinato de Sánchez Cerro en mayo de 1933, dio rápida solución a la peligrosa situación de preguerra, adversa a la inversión extranjera y nacional. Con sus medidas estabilizadoras Benavides se ganó pronto la confianza del capital privado, que no se fugó del país. Esta confianza de los particulares en el régimen autoritario de Benavides dio un cierto margen a la política de aumento crediticio e intervención del Estado 59.

Pero los intereses agrarios no deseaban un Estado intervencionista que fuera más allá de la ayuda directa a la agricultura. Los agricultores se oponían a una subida de las tasas de exportación, a la reforma del impuesto sobre la renta y al incremento del presupuesto, y favorecían una devaluación monetaria en momentos críticos ${ }^{60}$. Encabezados por el algodonero ultraliberal Pedro Beltrán, educado en Inglaterra, se creó en 1936 el Partido Nacional Agrario sobre la base de que el SNA formara una alianza electoral con el antiguo Partido Civilista. Los intereses de la exportación agraria visualizaban un Estado liberal y barato como el que existía antes de 1919. Políticamente, los agroexportadores eran conservadores y apoyaron la represión del partido aprista populista. Jorge Prado y su moderado movimiento «liberal» representaban, a la inversa, la continuación de la tendencia desarrollista e intervencionista ligada a los sectores de la élite que se orientaban a la industria y a la expansión del mercado interno. Prado prometía también la tolerancia para el influyente y desterrado partido APRA ${ }^{61}$.

Asi pues, la élite peruana se mostró dividida en las elecciones de 1936, por lo que los ricos sufrieron una fuerte derrota democrática. Antes de que las elecciones fueran declaradas nulas por Benavides - que siguió gobernando sin convocar otras elecciones hasta 1939-, el candidato apoyado por el APRA, Luis Eguiguren, era el claro ganador, seguido por el candidato fascista Luis Flores, heredero del difunto Sánchez Cerro ${ }^{62}$.

Las entidades financieras privadas de este periodo seguían la política crediticia conservadora y de alta liquidez del Banco Italiano. El Italiano habia reemplazado al fallido BPyL y heredado la importante estructura y mercado de las agencias provinciales controladas anteriormente por el banco peruano.

59 Romero (1945), Pp. 17-22; WCK, vol. 21, núm. 1121 (8 de agosto de 1933); 1.

60 «Los agricultores y la políticaw, La Vida Agricala, vol. 13, núm. 150 (1936), 385-386; Portocarrero (1983), pp. 28, 85-87.

61 Ibid., Pp. 22, 40; WCL, vol. 23, núm. 1245 (24 de diciembre de 1935), p. 1.

62 Portocarrero (1982). 
En la década de 1920 el Banco Italiano se había apartado de su política de concesión de créditos agrícolas y había desviado su estrategia hacia la expansión urbana y los mercados internos, más prometedores, sin perder la liquidez y movilidad de sus fondos y activos. Esta estrategia le dio buenos resultados.

El Banco Italiano reforzó la tendencia existente desde 1917 a que el total de los depósitos estuviera a un nivel más alto que el del total de los créditos y descuentos (véase figura 1). En el peor momento de la crisis económica el banco declaró unos buenos dividendos del 10 y el 8 por 100 para los años 1931 y 193263 . Sus reservas excedian cinco veces de las que exigia la ley. Además, el Banco Italiano contaba con el respaldo financiero italiano y suizo, lo que le permitió financiar el monopolio eléctrico (Empresas Eléctricas Asociadas), las obras del puerto del Callao, el oligopolio de la molienda de la harina y varias industrias oligopolisticas que estaban en manos de la primera o segunda generación de italianos ${ }^{64}$. En 1935 el Banco Italiano concentraba el $45 \%$ de los activos totales de los bancos comerciales y las cajas de ahorro (véase tabla III).

Como resultado de la recuperación de la exportación y de la expansión monetaria, los bancos comerciales habian experimentado un aumento de depósitos sin aparente adjudicación en otras direcciones. Los bancos no aumentaron sus créditos proporcionalmente. ¿Cómo siguieron obteniendo beneficios con unas obligaciones crecientes, no compensadas por mayores créditos? La respuesta está en una liquidez en aumento (fondos disponibles) que se utilizaba para comprar bonos de crédito público interno. Estos bonos se redescontaban en el Banco Central de Reserva. La fuerte liquidez permitía realizar operaciones muy provechosas con moneda extranjera y servir a exportadores e importadores (otras cuentas del pasivo) ${ }^{65}$. La Bolsa de Lima también se benefició de esta fuerte liquidez. Como consecuencia, el desarrollo financiero en este período de recuperación exportadora experimentó un importante avance.

63 «Annual General Meeting of Shareholders of Banco Italiano», WCL, vol. 20, núm. 1046 (1 may 1932), P. 4; «45the Annual Report of the Banco Italianow, WCL, vol. 21, núm. 1098 (7 de marzo de 1933), p. 21.

64 Cicarelli (1968):

65 Superintendencia, Memoria (1934-1940) y Situación de las empresas bancarias del Perí (Lima, 1931-1945); Portocarrero (1983), p. 21. 
En diciembre de 1939 Manuel Prado, el candidato favorito de Benavides, fue elegido presidente en medio de una sombria situación internacional. Prado había sido presidente del Banco Central entre 1934 y 193966 . Tenía considerable experiencia en el uso del crédito público interno para promocionar proyectos estatales. Su plan más ambicioso era la creación de compañías nacionales que desarrollaran los recursos nacionales desaprovechados: la Corporación del Amazonas (1942) y la Corporación Peruana del Santa (1943) ${ }^{67}$.

Estas empresas por parte del Estado carecian de una buena planificación y no dieron los resultados deseados, por los fondos limitados con que contaba el Estado, la dificultad de importar maquinaria durante la Segunda Guerra Mundial y la falta de financiación extranjera por el prolongado impago de 1931. Con un capital total proyectado de 100 millones de soles para la Corporación de Santa, en 1944 el Estado había entregado únicamente 8 millones.

Prado realizó también una osada política financiera expansionista. La emisión de bonos de deuda interna aumentó, y continuó el exceso de liquidez de los bancos. Esta política llegó a su límite cuando la inflación, la devaluación y la fuga de capitales hicieron de nuevo su aparición en los años 19381946. La respuesta de Prado fue imponer unos controles en los tipos de cambio y las importaciones, que causaron gran preocupación entre los exportadores. Sin embargo, las grandes firmas importadoras y los industriales que de ellas dependían apoyaron las medidas de control que favorecían las importaciones de bienes de inversión ${ }^{68}$.

Durante la Segunda Guerra Mundial la naciente industria peruana, como otras industrias latinoamericanas, tuvo grandes oportunidades para la sustitución de importaciones a pesar del alto coste de las mercancías esenciales de importación. Pero los importadores e industriales del Perú desaprovecharon estas oportunidades utilizando cuotas de importación sobrevaloradas y pagadas con la divisa extranjera barata que facilitaban los mecanismos de control estatal para el cambio y la importación establecidos por Prado. Los importadores $e$ industrialistas que de ellos dependian tenían en aquel momento vara alta en la política financiera.

os Banco Central de Reserva, Boletin menswal, 1934-1939.

67 Saint Maric (1945), pp. 112-120, 258-259. La Corporación del Amazonas Corporation explotaba caucho durante la Segunda Guerra Mundial. La Corporación del Santa era un complejo industrial e hidroeléctrico en el departamento de Ancash, «Memoria de la Corporación Peruana del Santan, Revista de Hacienda, vol. 26 (1946), p. 451.

68 Portocarrero (1983), p. 33. 
La producción industrial nacional aumentó, pero las importaciones peruanas subieron espectacularmente de valor en 1943. El comercio extranjero, que desde 1933 había dado beneficios, se volvió negativo. Esto se debió a una política de importaciones que era demasiado vulnerable a la subida de los precios internacionales en las importaciones básicas peruanas (maquinaria y vehículos, alimentos, productos quimicos industriales, aparatos eléctricos). Surgió la inflación ${ }^{69}$. Este es un caso de desaprovechamiento de unas oportunidades de desarrollo, que distorsionó la adjudicación de los recursos, la distribución de la renta y la capacidad empresarial por el apoyo que los importadores y los industriales prestaron a la represión financiera ejercida por el Estado ${ }^{70}$.

La confianza de la élite en las medidas financieras del Estado descendió aún más cuando persistieron el control y los aumentos de salario bajo el régimen de José $\mathrm{L}$. Bustamante (1945-1948). La inflación aumentó hasta alcanzar un peligroso $45 \%$ en 1946, cuando en 1945 había sido de un 7,1\% y en 1944 de un 2,9\%. Como consecuencia, los depósitos comerciales, los ahorros y los activos nos muestran un considerable declive entre 1946 y 1950 en la figura 171 .

El peso del algodón y el azúcar en las exportaciones peruanas también inició su reducción a largo plazo, a pesar de su último resurgimiento en 1951. Por tanto, la antigua influencia de los intereses exportadores agrarios se desdibujó. Los grupos de élite y los nuevos capitalistas controlaban ahora la dependiente producción industrial y la reciente industria pesquera floreció con la ayuda del sector comercial bancario 72 .

La política más significativa del sector comercial bancario, que se adaptó rápidamente a las cambiantes condiciones económicas, fue la concesión de importantes créditos a estos nuevos sectores. Por fin, en la década de 1960 comenzaron a aparecer los bancos regionales ${ }^{73}$. Nuevos métodos financieros transformaron el carácter anterior de la estructura financiera, apartándola del

69 Arca Parró (1945), pp. 49, 53-54; Ferrero (1945), pp. 342-343; «Memoria del Banco Industrial del Perún en Perú, ministro de Hacienda (1941), p. 755; «La inflación puede considerarse como un ahorro forzado...n de acuerdo con Rómulo Ferrero, primer ministro de Hacienda del régimen de José L. Bustamente, Perú, ministro de Hacienda (1946), vol. I, p. 245.

70 «El Banco Industrial y la agricultura», La Vida Agricola, vol. 13, núm. 157 (1936), pp. 935938; Portocarrero (1983), pp. 43-45; críticas a estrategias de industrialización basadas en altas ganancias, financiamiento interno y represión financiera en Garrido-Lecca y O’Mara (1974), pp. 48-49.

71 Jelicic (1947), pp. 254-268.

72 Thorp y Bertram (1978), pp. 211, 245; Roemer (1970).

73 «Público alegato ante la superintendencia de bancos sustentando la creación del Banco del Norte del Perú y demás bancos regionales", El Comercio, 10 de junio de 1960, pp. 10-11. 


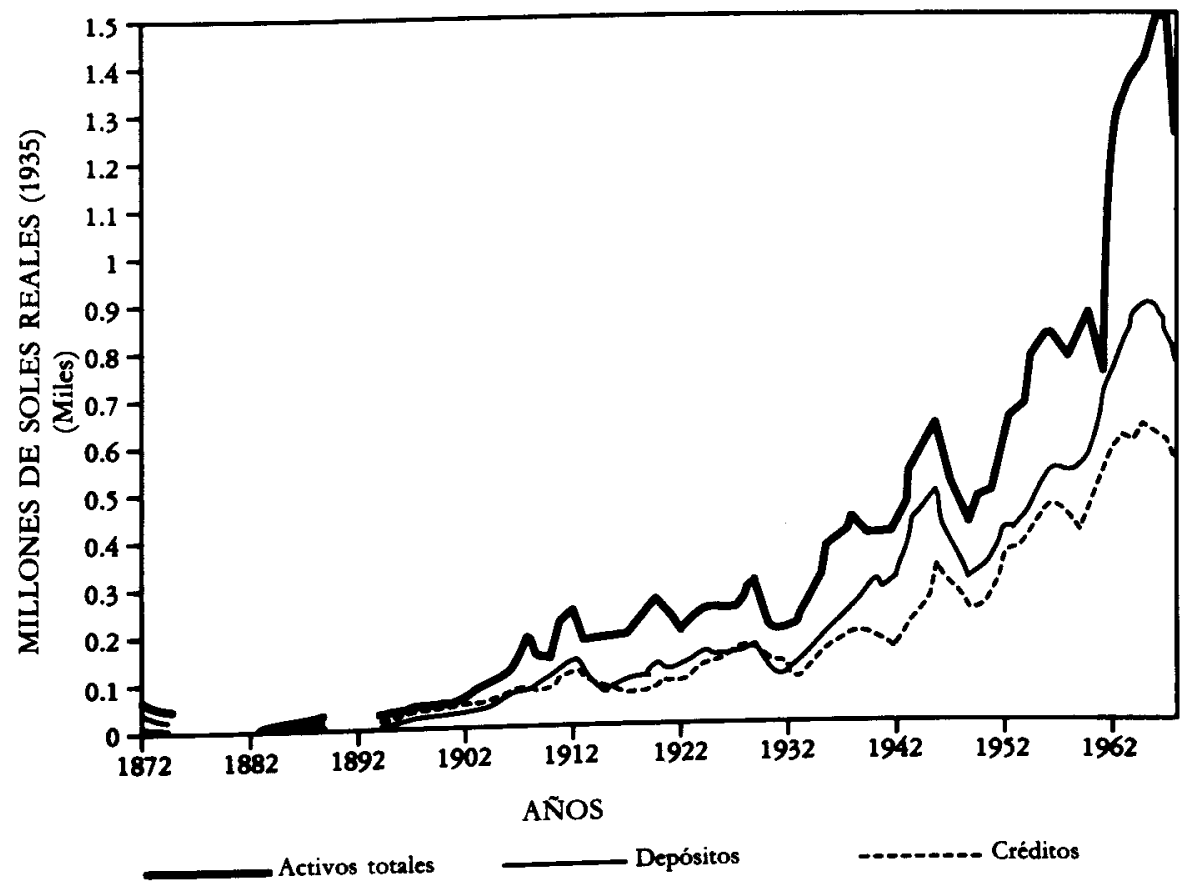

FIGURA 1

Bancos comerciales $y$ de aborro

(activos totales, depósitos y créditos, 1872-1968).

Nota: Las cantidades corrientes han sido deflactadas por el indice de precios al por mayor de 1909-1949, y el deflactor implicito del PNB en 1950-1968; el indice de precios de 1891 estimado por Shane Hunt; los deflactores de los años que restan son extrapolaciones y estimaciones basadas en los tipos de cambio.

FUENTES: Camprubi (1957), Pp. 217, 234; conjunto de balances de entidades individuales en $E$ l comercio y El Financista (Lima, 1883-1917); Inspección Fiscal de Bancos, Informe (Lima, 1921-1930); Extracto Estadistico (1918-1944); Anvario Estadistico (1944-1966); Superintendencia de Bancos, Memoria (1931-1966); Hunt (1980); Superintendencia General de Aduanas, Estadistica general del comercio del Perń, 1891 (Lima, 1892), II, 27-31.

exceso de liquidez o de la influencia agroexportadora ${ }^{74}$. El Banco Continental fue fundado en 1951 por hábiles financieros como Alfredo Alvarez Calderón, que vio las posibilidades que brindaban al sector industrial los métodos de financiación a largo plazo ${ }^{75}$. Este banco aceptó la participación extranjera, como hicieron otras entidades nacionales (incluido el Banco de Crédito) que

74 Ordóñez (1963), Basombrio Zender (1979), Cuchiarelli (1973); superintendencia, Memoria, 1968-1988.

75 La Prensa, vol. núm. 24.615 (1956), xiv-xviii. 
controlaban del 92 al $95 \%$ del total de activos comerciales bancarios desde 1945 (tabla II). Como consecuencia, el capital extranjero incrementó su influencia sobre la estructura financiera peruana. De esta forma la financiación industrial parece que obtuvo una cierta diversificación, a costa de ver disminuir su autonomía.

Conviene ahora llegar a algunas conclusiones generales tras esta exposición de datos sobre las sucesivas fases del desarrollo financiero peruano. Volvamos a la primera de nuestras dos preguntas básicas. ¿Ayudó el sistema financiero peruano a la diversificación productiva y autónoma de la economía de exportación? Según la figura 2, el crédito concedido por el sector. comercial bancario evidencia: a) un viraje a largo plazo desde los sectores agrícolas, de la construcción, y gubernamentales, hacia el sector industrial, y b) un aumento del ya alto porcentaje de crédito concedido al comercio. El continuado aumento de los porcentajes concedidos a la industria y el comercio deben, pues, identificarse con una limitada modernización y diversificación de la economia de exportación peruana y de su superestructura financiera.

El desarrollo financiero peruano fue positivo, pero inestable. Las considerables fluctuaciones de los indicadores financieros de la tabla I limitaron el impacto de la estructura financiera sobre una diversificación más productiva. Como hemos visto, por un lado la extrema especialización de los agroexportadores y las pérdidas sufridas durante las caidas de la exportación (sobre todo, entre 1927 y 1932) retrasaron el desarrollo financiero. Los intereses agrarios lograron diversificarse hasta cierto punto en años posteriores, por medio de la formación de grupos. Pero en las décadas de 1930 y 1940 la inversión alternativa y la adjudicación de créditos se vieron limitadas por la expansión de un mercado interno oligopolistico y dependiente de la importación.

La intervención y la reglamentación financiera del Estado contribuyeron sobre todo a una creciente infraestructura de carreteras y planes de regadio y de puertos en los años 20 y 30 , bien por endeudamiento con el exterior, bien por financiación "autónoma» interna. Sin embargo, cuando el Estado intentó proteger los intereses industriales con el control financiero y la represión los efectos fueron negativos para la estructura financiera nacional.

Los acreedores e inversores extranjeros se esforzaron por controlar los 


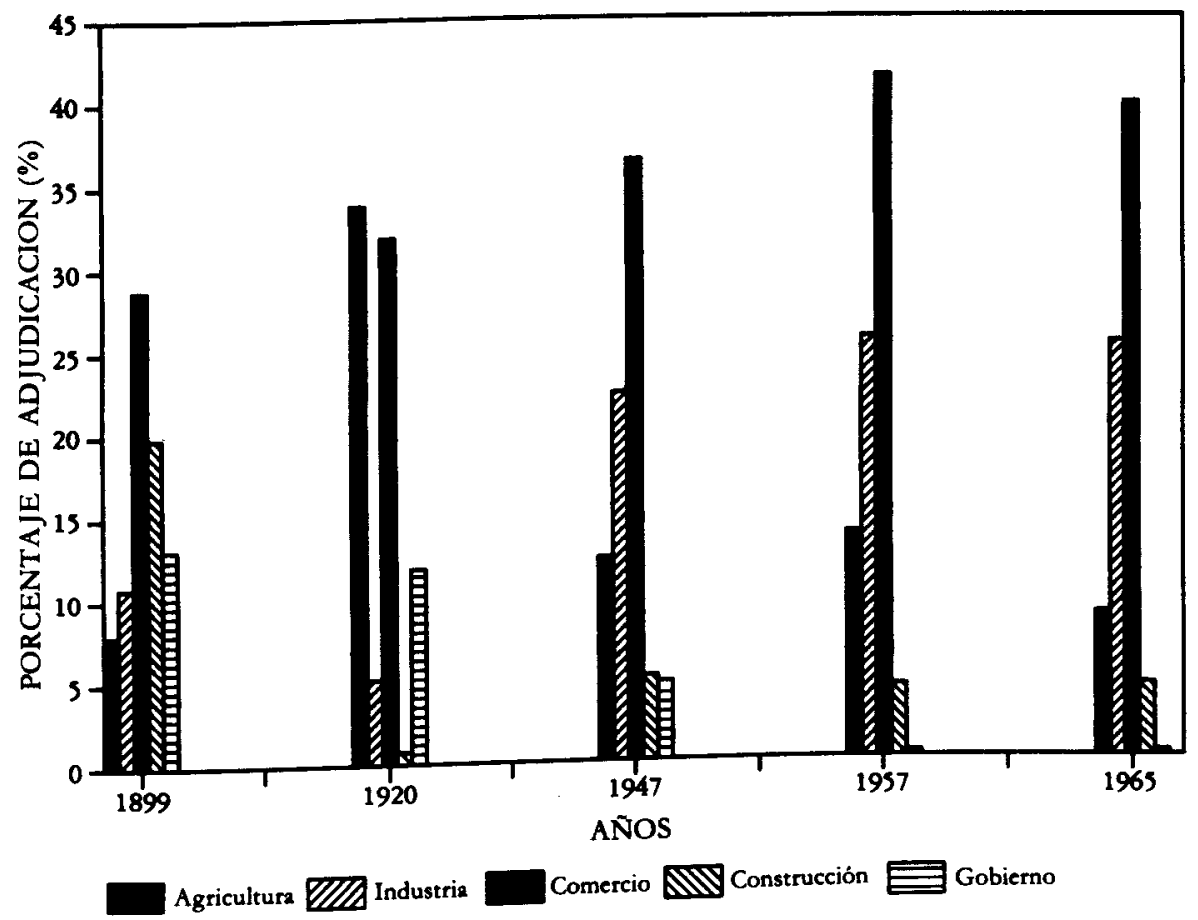

FIGURA 2

Adjudicación del crédito por sectores

(\% de préstamos comerciales, 1899-1965)

Nota: Los porcentajes para los años 1899 y 1920 son estimaciones basadas en préstamos y descuentos de una sola institución bancaria (aunque fuera la principal en aquel momento) en los períodos de 1899-1906 y 1920-1925. A partir de 1947, existen datos oficiales de conjunto sobre la adjudicación sectorial del crédito.

Fuentes: Banco del Perú y Londres, *Actas y reuniones del Directorio*, 1897-1930, 17 vols., y "Actas de reuniones del Comité de Directoriow, 1914-1930, 12 vols., BPLS; Superintendencia de Bancos, Memoria (1947-1969); Amuario estadístico, 1954-1966.

sectores estratégicos, incluido el campo financiero nacional. En un principio lograron controlar el ferrocarril, la minería, el petróleo, el comercio agricola e incluso algunas empresas financieras que desplazaron a los inversores peruanos. Pero los sectores agrario y financiero resultaron ser un hueso duro de roer por la importante representatividad que en ellos tenían los nativos. En esta búsqueda de una mínima y relativa autonomía fue donde la élite financiera peruana logró competir y sobrevivir.

De cierta manera importante, los agroexportadores demostraron ser más 
«autónomos» que los dependientes industrialistas. La élite agraria de exportación era el sector clave del capitalismo peruano y su ramificación financiera y política. Ella suministró un núcleo central costero, un polo de desarrollo y acumulación necesario en todo proceso capitalista. Históricamente esto se consiguió en el período de 1890-1914 con una política financiera conservadora en sus inicios, basada en el patrón oro, comercial a corto plazo y en su mayor parte privada. El capital extranjero, básicamente inglés y francés, participó en este proceso (por la debilidad económica peruana después de la guerra con Chile), lo que planteó serias amenazas, que con el tiempo no se materializaron, al carácter nativo de la estructura financiera peruana y de la propiedad agraria.

Las condiciones extremadamente favorables de la exportación durante la Primera Guerra Mundial para la élite agraria (no para las clases populares), consolidó una temporal e importante autonomia financiera del sector exportador agrario y su financiación. Los terratenientes pudieron no sólo devolver anteriores deudas particulares a los acreedores extranjeros, sino participar activamente en el control y transformación de la estructura financiera peruana.

Después de la crisis de 1929-1932, el reestructurado y concentrado sector bancario comercial volvió a caer en una política bancaria conservadora, de alta liquidez, que encabezaban los bancos Italiano y de Crédito. Los servicios bancarios privados viraron hacia los intereses comerciales urbanos y el crédito industrial, más seguros, y hacia las beneficiosas operaciones de cambio, con preferencia a la financiación del sector agrario de exportación.

Los intereses agrarios presionaron sobre el Estado solicitando apoyo financiero en la década de 1930. Se puso en marcha un banco agricola financiado por el Estado, que resultó beneficioso sobre todo a los plantadores de algodón. Desde 1933 se logró una recuperación general por una mejoría en los precios internacionales del algodón, el impago de la deuda exterior y una política financiera y monetaria estatal autónoma, expansionista y no basada en el patrón oro. Todas estas medidas fueron favorables a los intereses exportadores. Por tanto, la élite costera agraria, disminuida en su posición económica, mantuvo su influencia sobre los principios básicos de las finanzas nacionales.

Pero si hay pruebas del papel que desempeñó el sistema financiero en una relativa y limitada diversificación productiva y autónoma, jcontribuyó la estructura financiera peruana a una distribución social y regional más humanitaria de los fondos? La terminación bajo la presidencia de Benavides de las obras públicas básicas, proyectadas diez años antes por Leguía, aceleró por fin 
el impacto de la dinámica capitalista en las regiones del interior. Pero el retraso de este impacto tal vez fuera crucial para un equilibrado desarrollo nacional.

Los recursos financieros siguieron concentrándose en Lima y en la región costera, como muestra la tabla III. Después de 1935 los créditos y depósitos de los bancos comerciales de provincias, aparte de Lima, no sobrepasaron el $28 \%$ del total. Asimismo, la costa recibió más del $90 \%$ de los créditos comerciales desde 1945. Los créditos hipotecarios en provincias muestran un asombroso descenso desde el $23 \%$ en 1894 , hasta el $2 \%$ en 1965 . Hasta los bancos de desarrollo contribuyeron a la concentración financiera en la costa y en Lima. En 1945 el Banco Agrícola asignó a la costa el $68 \%$ de sus créditos y el Banco Industrial el $87 \%$. Este último también concedió únicamente el $27 \%$ de sus créditos a otras provincias que no fueran Lima.

Las regiones se vieron adversamente afectadas por la paralización de las obras públicas en 1929 y por la lenta transición de los grupos provinciales de élite a campos que rebasaban los intereses comerciales y terratenientes. En las provincias los bancos se dedicaban sobre todo a realizar servicios comerciales y a operaciones de transferencia de fondos hasta la aparición de los bancos regionales en la década de los 60 . Las regiones no pudieron imponerse al centralismo limeño, en parte por las limitaciones de los mercados y la producción provincial, mediatizados por los intereses tradicionales de terratenientes y campesinos ${ }^{76}$.

Los bancos se desinteresaron del pequeño ahorro, que quedó a merced de los mercados extraoficiales hasta la década de 1920 . La depresión de los 30 y la inflación de los 40 desmoralizaron a los pequeños ahorradores que se vieron afectados por unas politicas monetarias oficiales adversas. Del mismo modo, el crédito oficial a los pequeños productores fue prácticamente inexistente hasta hace pocos años, como demuestra el fallo del Banco Agrario en la concesión de crédito a los pequeños propietarios de tierras. En general, los sectores populares no se beneficiaron directamente de la evolución financiera pública y privada. La economía de exportación peruana se modernizó en parte entre 1884 y 1950 gracias a su estructura financiera nacional, pero el país fue incapaz de alcanzar el objetivo, más alto, de un desarrollo equilibrado. 


\section{BIBLIOGRAFIA}

Albert, Bill (1976): «An Essay on the Peruvian Sugar Industry 1880-1920», Norwich, Norfolk, University of East Anglia.

(1988): South America and the First World War: the Impact of War on Brazil, Argentina, Perw and Cbile, Cambridge, Cambridge University Press.

Arca Parro, Alberto (1945): "Perú en cifras", en Saint Marie (1945), pp. 49-54.

Aspillaga, Antero; Garland, Alejandro, y LeguiA, Augusto (1902): La crisis del aqúcar: informe de la comisión oficial, Lima, Ministerio de Fomento.

ASPILlAGA, Antero; DUBOIS, Luis, y GILDEMEISTER, Juan (1892): Informe en mayoría de la comisión para el estudio de la depreciación en el valor de la moneda nacional de plata, Lima.

BanCo De Reserva del Perú (1922-1930): Memoria, Lima.

BASADRA, Jorge (1968): Historia de la República del Perú, Lima, Editorial Universitaria. BASCH, Antonin (1966): El mercado de capitales de Colombia, México.

BASOMBRIO ZENDER, Ignacio (1979): Bancos: elementos para un debate, Lima.

BenefiCencia PUbliCa de Lima (1909-1929): Memoria de las operaciones de la Caja de Aborros, Lima.

BergQUIST, Charles (1979): Alternative Approaches to the Problem of Development: $A$ Selected and Annotated Bibliography, Durham, Duke University Press. (1988): Labor in Latin America, Stanford: Stanford University Press.

BERRAM, Geoffrey (1977): «Modernización y cambio en la industria lanera del Perú, 1919-1930: un caso frustrado de desarrollo», Apwntes, núm. 6, pp. 3-22.

BolonA, Carlos (1981): "Tariff Policies in Peru, 1880-1980«, tesis doctoral, University of Oxford.

BOLSA COMERCIAL de Lima (1900-1914): "Memoria anual», en Boletín de la Bolsa Comercial, Lima.

Bravo Holguin, J. (1966): Evolución de las instituciones financieras en Colombia, México.

Caja de Depósitos y Consignaciones (1925): Memoria, Lima.

CAMPRUBi, Carlos (1957): Historia de los bancos en el Perú, Lima, Lumen.

- (1968): Un siglo al servicio del aborro: 1868-1968, Lima, P. L. Villanueva.

Cariola, Carmen, y SUNKEL, Osvaldo (1985): "The Growth of the Nitrate Industry and Socioeconomic Change in Chile, 1880-1930m, en Cortes Conde y Hunt (1985), pp. 137-254.

Cicarelli, Orazio (1988): «Fascist Propaganda and the Italian Community in Peru durinh the Benavides Regime, 1933-1939», Journal of Latin American Studies, vol. 20 , pp. $361-388$.

Cisneros, C. (1912): Simopsis estadística del Perú, 1908-1912, Lima, Imprenta Unión.

COATSWORTH, John (1981): Growth Against Development: the Economic Impact of Railroads in Porfirian Mexico, DeKalb, Northern Illinois University Press.

COBO DEL PRADO, M., y GARRIDO LECCA, Guillermo (1972): Estudio piloto de activos y pasivos financieros en el Perú $y$ sus interrelaciones sectoriales en el periodo 1965-1970, Simposio sobre el Mercado de Capitales en el Perú, Comisión Nacional de Valores, Lima.

CORDERO, Maria (1976): «Evolución financiera de México: Porfiriato y Revolución», Revista Mexicana de Sociologia, 38-2 (1976), pp. 359-387. 
CORRea y SANtIAgo, Pedro, y PAYAN, José (1892): Informe en minoria de la comisión para el estudio de la depreciación en el valor de la moneda nacional de plata, Lima.

CORTÉs CONDE, Roberto, y HUNT, Shane (1985): The Latin American Economies: Growth and the Export Sector, 1880-1930, Nueva York, Holmes \& Meier Publishers.

Cuchiarelli, Paolo (1973): «Futuro de la banca privada frente al crecimiento de la banca asociada», Lima.

DiEz CASECO, Octavio (1960): De espaldas al desarrollo agrario permano, Lima.

DORE, Elizabeth (1988): The Perwian Mining Industry: Growth, Stagnation, and Crisis, Boulder, Westview Press.

Drake, Paul (1989): The Money Doctor in the Andes: The Kemmerer Missions, 1923-1933, Durham, Duke University Press.

Ferrero, Rómulo (1945): «El comercio en el Perú», en Saint Marie (1945), Pp. $242-$ 343.

FORD, Alec G. (1983): The Gold Standard, 1880-1914: Britain and Argentina, Nueva York, Garland Publishing.

(1985): "Notes on the Working of the Gold Standard Before 1914», en EICHENGREeN, Barry, ed., The Gold Standard in Theory and Practice, Londres, pp. 141-165.

GARLAND, Alejandro (1908): Sistema monetario del Perí, Lima, Imprenta La Opinión Nacional.

GARRIDO-LECCA, Guillermo, y O'MARA, Gerald (1974): The Urban Informal Credit Market in a Developing Country Under Financial Repression: the Perwian Case, Austin, University of Texas Press.

GoDOY, Joaquín, ed., (1890-1897): Revista de Cambios y Valores, Lima.

GOLDSMITH, Raymond (1966): The Financial Development of Mexico, París, OECD.

- (1969): Financial Structure and Development, New Haven, Yale University Press. (1985): Comparative National Balance Sbeets: A Study of Twenty Countries, 16881978, Chicago, University of Chicago Press.

(1987): Premodern Financial Systems: A Historical Comparative Study, Cambridge, Cambridge University Press.

Gonzales, Michael (1985): Plantation Agriculture and Social Control in Northern Pern, 1875-1932, Austin, Texas University Press.

Harvey, Héctor (1936): "El Banco Agricola del Perú», en La Vida Agricola (Lima), vol. 13, núm. 152.

HOOPER LÓPEZ, René (1964): Leguia: ensayo bibliográfico, Lima.

HUNT, Shane (1980): «Evolución de los salarios reales en el Perú: 1900-1940w, Economia, núm. 3, pp. 83-123.

(1985): «Growth and Guano in Nineteenth Century Peru», en Cortés Conde y Hunt (1985), Pp. 255-318.

INFORMACIONES MERCANTILES E INDUSTRIAles (1921): El Perí en su centenario, Lima,

Sanmartí.

INSPECCIÓN FisCal de COMPANIAS DE SEguROS (1903): Memoria del Director en 1902, Lima.

JELICIC, Jorge (1947): «La Memoria del Banco de Reserva y la situación económica

del Perún, Mercurio Perwano, núm. 242, pp. 254-268. 
KLAREN, Peter (1973): Modernization, Dislocation, and Aprismo: Origins of the Peruvian Aprista Party, 1870-1932, Austin, University of Texas Press.

KLAREN, Peter, y Bossert, Thomas (1986): Promise of Development: Theories of Change in Latin America, Boulder, Westview Press.

KLINGE, Gerardo (1945): «La agricultura en el Perú», en Saint Marie (1945), PP. 73-75.

—_ (1935): «Política de Irrigación», La Vida Agricola, vol. 13, núm. 137, Lima.

LEFF, Nathaniel (1976): "Capital Markets in the Less Developed Countries: The Gruop Principle», en MCKINNON, Ronald, ed., Money and Finance in Economic Growth and Development, Nueva York.

LEGUí, Augusto [?] (1936): El Oncenio y la Lima actual: memorias completas del Presidente Leguia "Yo tirano, yo ladrón", Lima, Imprenta J.C.L.

Lough, William (1915): Baking Opportunities in South America, U. S. Department of Commerce, Special Agents Series, núm. 106, Washington, GPO.

Ludlow, Leonor, y MARICHal, Carlos (1986): Banca y poder en México, 1800-1925, México.

Mallon, Florencia (1983): The Defense of Community in Peru's Central Highlands: Peasant Struggle and Capitalist Transition: 1860-1940, Princeton, Princeton University Press.

MalPiCA, Carlos (1977): El mito de la ayuda exterior, Lima.

Marichal, Carlos (1988): Historia de la deuda externa de América Latina, Madrid, Alianza Editorial.

MAYER, Dora (1906): «Moralidad en los negocios», La Gaceta Comercial, vol. 6, núm. 123, Lima.

MCKInNON, Ronald (1973): Money and Capital in Economic Development, Washington, Brookings Institution.

MELleR, Ignacio (1932): Patrón de oro o bimetalismo: ensayo sobre aspectos nuevos de un problema antiguo, Lima, Gil.

MILLER, Rory (1976): "The Making of the Grace Contract: British Bondholders and the Peruvian Government, 1885-1890», Journal of Latin American Studies, núm. 8, pp. 73-100.

MOORES, O. Ernest (1963): Evolución de las Instituciones financieras en México, México.

MORRIS, Cynthia T. (1984): "The Measurement of Economic Development: Quo Vadis?", en RANIS, Gustav et al., eds., Comparative Development Perspectives, Boulder, Westview Press.

Olivares, Rubén L. (1923): El negocio del dinero y la usura, Lima, Sanmartí.

ORDÓNEZ, Mario B. (1963): La técnica y la práctica en la banca peruana, Lima.

PAYAN, José (1892): La cuestión monetaria en el Perú, Lima, Imprenta Torres Aguirre.

PERÚ, Cámara de Diputados (1921): Dictamen de la comisión parlamentaria investigadora de la Compañia Recaudadora de Impuestos, Lima, Imprenta $T$. Scheuch.

_- Ministro de Hacienda (1941) y (1946): Memoria, Lima.

PORTOCARRERO, Gonzalo (1982): «La oligarquía frente a la reivindicación democrática (las opciones de la derecha en las elecciones de 1936)", Apuntes, núm. 12, pp. 61-73.

(1983): De Bustamante a Odria: El fracaso de Frente Democratico Nacional, $1945-$ 1950, Lima, Mosca Azul. 
QUIROZ, Alfonso W. (1986): «Financial Institutions in Peruvian Export Economy and Society, 1884-1930», tesis doctoral, Columbia University.

RAMIREZ, Elia (1985): Estadisticas bancarias: promedios anuales de los balances menswales de los bancos mexicanos, 1822-1910, México.

RAMIREZ GASTÓN, José (1904): Sociedades de crédito agricola mutual, Lima.

- (1964): Medio siglo de la política económica y financiera del Perú, Lima.

REYNOLDS, Clark (1973): «Flow of Funds: The Use of the Flow of Funds Analysis in the Study of Latin American Capital Market Development», en Organización de Estados Americanos, Capital Markets Development Program, III Reunión Anual, México.

Roberts, Bryan (1976): "The Social History of a Provincial Town: Huancayo, 1890 1972», en Miller, Rory et al., Centre for Latin Studies, Monograph Series núm. 6.

RoDRigueZ, Jorge, y William MCGREEVEY (1970): «Colombia: comercio exterior, 1835-1962», en URRUTIA y ARRUBIA (1970).

ROEMER, Michael (1970): Fishing for Growth: Export-Led Development in Peru, 19501967, Cambridge, Mass., Harvard University Press.

ROMERO, Emilio (1945): «La evolución económica en el Perú», en Saint Marie (1945), Pp. 17-22.

ROSE, Peter (1987): The Changing Structure of American Banking, Nueva York.

SaINT MARIE, Darío (1945): El Perú en cifras, Lima. Development, Austin, University of Texas Press.

Solfs, Leopoldo (1970): La realidad económica mexicana: retrovisión y perspectivas, México. Solis, Leopoldo, y BROTHERS, Dwight S. (1966): Mexican Financial Development, Austin, University of Texas Press.

STAllingS, Barbara (1987): Banker to the Third World: U. S. Portfolio Investment in Latin America, 1900-1986, Berkeley, University of California Press.

TAmayo Herrera, José (1981): Historia social del Cuzco republicano, Lima, Editorial Universo.

THORP, Rosemary (1972): «La función desempeñada por las instituciones financieras en el proceso de ahorro peruano, 1960-1969", Simposio sobre el Mercado de Capitales en el Perú, Comisión Nacional de Valores, Lima.

THORP, Rosemary, y BERTRAM, Geoffrey (1978): Peru 1890-1977: Growth and Policy in an Open Economy, Nueva York, Columbia University Press.

TOPIK, Steven (1987): The Political Economy of the Brazilian State, Austin, Texas University Press.

UGARTECHE, Pedro (1930): La política internacional perwana durante la dictadura de Leguia, Lima.

Urrutia, M., y ARrubia, M. (1970): Compendio de estadisticas bistóricas, Bogotá.

U. S. DEPARTMENT OS STATE (1936): Papers Relating to the Foreign Relations of the United States, 1921, Washington, D.C., GPO.

WEAVER, Frederick S. (1977): "Neo-Classical Theory, Dependency Theory and the Staple Theory", Occassional Papers Series núm. 7, Amherst, University of Connetticut.

(1980): Class, State, and Industrial Structure: The Historical Process of South American Industrial Growth, Westport, Greenwood Press. 
Wilson, Fiona (1987): «The Conflict Between Indigeneous and Immigrant Commercial Systems in the Peruvian Central Sierra, 1900-1940m, en Miller, Rory et al. (1987): Region and Class in Modern Perwian History, Manchester, University of Liverpool.

YEPES, Ernesto (1972): Perí 1820-1920: un siglo de desarrollo capitalista, Lima, IEP. ZABLUDOWSKI, Jaime E. (1984): «Money, Foreign Indebtedness and Export Performance in Porfirist Mexico», tesis doctoral, Yale University. 